\title{
Pareceres, juristas e apedeutas
}

\author{
Eras Robexto Exau
}

Professor Titular da Faculdade de Direito da Universidade de São Paulo.

1.

Ao profissional do direito incumbe o desempenho de tarefas destinadas à provisão da interpretação/ aplicação do direito, operação que, ao contrário do que costumam alguns imaginar, não é constituída de duas etapas, consubstanciando uma só e única atuação processual. Quem interpreta, aplica; e só: nada se interpreta, no mundo do jurídico, senão para que o resultado da interpretação (= a norma jurídica) se aplique a determinada situação de conflito, efetiva ou potencial. $^{1}$

O desempenho daquelas tarefas requer qualificação intelectual obtenível em instituições de ensino superior, as Faculdades de Direito.

O que assim desejo afirmar, de modo simplório, é que, muito ao contrário também do que tantos supõem, não basta a alfabetização para que o leigo "interprete o direito", tal como não basta o conhecimento do manejo de lâminas para que o leigo pratique operações cirúrgicas no ser humano (ou mesmo em outros animais) e não basta a aptidão para a prática das quatro operações aritméticas para que um outro realize operações de cálculo de estruturas ou de concreto. Quem é dotado de prudên. cia sabe que assim como não deve o sapateiro ir além dos sapatos, não apenas não devem os apedeutas em medicinas e enge. nharias arriscar-se na manipulação de bisturis e de réguas de cálculo, mas também, os que não são dotados de formação jurídica, meter-se a "interpretar" o direito e a discutir as leis. Se aqui não há mortes, há seguramente penas, quando a estultice leva o incauto a cruzar as linhas do ilícito e da ilegalidade.

Apedeutas bem intencionados recorrem a advogados e, nas complexidades, a juristas.

2. A prática de pedir-se aos juristas opiniões sobre questões determinadas remonta ao passado. A jurisprudência romana

1. Sobre direito e conflito, meu $O$ direito posto e o direito pressuposto. 2. ed., São Paulo: Malheiros Editores, 1998, pp. 20-21. 
era constituída pela obra dos jurisconsultos, essencialmente as responsa, respostas dadas a consultas que lhes eram apresentadas. Jurisprudência, como observa GILISSEN, ${ }^{2}$ é vocábulo que designa o que as línguas novilatinas chamam de doutrina. A iurisprudentia, anota BARTOLOME CLAVERO, ${ }^{3}$ é o consulting romano, a obra dos iurisconsulti, assessores de direito, como também eram chamados os prudentes ou iurisprudentes.

Esses juristas, prudentes conselheiros, eram dotados de uma autoridade que não era nem política, nem judicial - tratava-se, aí, de uma autoridade intrínseca, fundada em um capital intelectual próprio, não em qualquer poder que tivesse sido a eles atribuído. ${ }^{4} \mathrm{~A}$ autoridade das suas consultas, diz GILISSEN,${ }^{5}$ decorria do seu valor pessoal e do seu prestígio social.

3. Assim é (ou deveria ser) nos tempos de hoje.
A autoridade dos juristas que respondem a consultas elaborando pareceres é construída não apenas sobre o capital intelectual acumulado mercê de efetiva dedicação ao estudo do direito, mas também sobre a sua prudência e sobre sua seriedade intelectual. ${ }^{6}$ De nada vale a sabedoria para o imprudente e para quem responda a consultas não segundo a sua convicção, mas conforme os desígnios de quem as encomenda e paga.

O jurista dá resposta aos quesitos que Ihe foram propostos esclarecendo qual o direito aplicável à hipótese objeto da consulta. Empreende, para tanto, atividade de interpretação do direito.

4. Esta, a interpretação, ${ }^{7}$ implica compreensão e reprodução: o sentido expressado pelo texto normativo é compreendido pelo intérprete, que o reexprime sob a forma de norma jurídica. Por isso, sustento ser o texto (preceito, enunciado
2. Introdução histórica ao direito, trad. de A. M. Hespanha e L. M. Macaísta Malheiros. Lisboa: Fundação Calouste Gulbenkian, 1986, p. 90.

3. Institucion historica del derecho. Madrid: Marcial Pons, 1992, p. 22.

4. Cf. CLAVERO, Bartolome, ob. e loc. cits.

5. Ob. e loc. cits.

6. Entenda-se como prestígio social do jurista, hoje, não aquele apregoado pelos meios de comunicaçős, alimentado por equipes de relaçōes públicas contratadas por determinados "juristas", mas sim o conquistado pelo profissional do direito entre seus próprios pares.

7. Vide meus La doppia destrutturazione del diritto, trad. de Elisabetta Albesano. Milano: Unicopli, 1997, pp. 55 e ss.; La doble desestructuración del derecho, trad. de Barbara Rosenberg. Barcelona: Bosch, 1998, pp. 65 e ss.; e $O$ direito posto e o direito pressuposto, cit., pp. 153 e ss. A interpretação consubstancia uma operaçăo de mediação que opera a transformação de uma expressáo em outra, visando tornar mais compreensivel o objeto ao qual a linguagem se aplica. Observei, em meu La doppia destrutturazione del diritto (cit., p. 59) que "Linterpretazione dunque è un processo intellettivo tramite il quale, partendo da formule linguistiche contenute nei testi, enunciati, precetti, disposizioni, si stabilisce un contenuto normativo. Questa attività interpretativa è volta al discernimento degli enunciati semantici veicolati dai precetti (enunciati, disposizioni, testi). (...) Interpretare è attribuire un significato a uno o più simboli linguistici scritti in un enunciato normativo" (na edição espanhola, cit., p. 68). Dai a necessidade de considerarmos a distinção entre texto e norma, que permite ao intérprete observar que nem sempre um e outra -0 texto normativo e a norma - correspondem, seja porque determinada norma pode ser produto da interpretacăa coniunta -0 lex um texto normativo, seja porque um mesmo texto normativo pode ser moldura para a produção de mais de uma norma.

Revista da Faculdade de Direito da UFRGS, v. 18, 2000 normativo) alográfico. Não se completa no sentido nele impresso pelo legislador. A "completude" do texto somente é realizada quando o sentido por ele expressado é produzido, como nova forma de expressão, pelo intérprete. Mas o "sentido expressado pelo texto" já é algo novo, distinto do texto: é a norma.

Isso significa que o texto normativo, visando à solução de conflitos (isto é, uma decisão normativamente fundada para problemas práticos), reclama um intérprete que compreenda e reproduza a fim de que um determinado conflito seja decidido.

A interpretação do direito opera a mediação entre o caráter geral do texto normativo e sua aplicação particular: isto é, opera a sua inserção na vida.

5. Cumpre insistir, ademais, em que interpretação e aplicação não se realizam autonomamente. O intérprete discerne o sentido do texto a partir e em virtude de um determinado caso dado; ${ }^{8}$ a interpretação do direito consiste em concretar a lei em cada caso, isto é, na sua aplicação. ${ }^{9}$ Assim, existe uma equação entre interpretação e aplicação: não estamos, aqui, diante de dois momentos distintos, porém frente a uma só operação. ${ }^{10}$ Interpretação e aplicação se superpõem.
Ora, sabendo que interpretar o direito é concretar a lei em cada caso, ou seja, é aplicar ${ }^{11}$ a lei, diremos que o intérprete sempre discerne o sentido do texto a partir e em virtude de um determinado caso dado. Sendo, a interpretação, concomitantemente aplicação do direito, deve ser entendida como produção prática do direito, como a toma FRIEDRICH MÜLLER, ${ }^{12}$ para quem inexiste tensão entre direito e realidade; não existe um terreno composto de elementos normativos, de um lado, e de elementos reais ou empíricos, do outro. ${ }^{13}$

Isso significa que a norma é produzida não apenas a partir de elementos que se despreendem do texto (mundo do deverser), mas também a partir de elementos do caso ao qual será ela aplicada, isto é, a partir de elementos da realidade (mundo do ser).

$O$ que incisivamente deve aqui ser afirmado, desde a metáfora de KELSEN,,$^{14}$ é o fato de a "moldura da norma" ser, diversamente, moldura do texto, mas não apenas dele; ela é, concomitantemente, moldura do texto e moldura do caso. O intérprete interpreta também os fatos que consubstanciam o caso, necessariamente,

8. Cf. GADAMER, Hans-Georg. Verdad y metodo. Cuarta edición, trad. de Ana Agud Aparicio y Rafael de Agapito. Salamanca: Ediciones Sigueme, 1991, p. 397.

9. Idem, p. 401.

10. Cf. MARI, Enrique E. "La interpretacion de la ley. Análisis histórico de la escuela exegética y su nexo con el processo codificatorio de la modernidad". In Materiales para una teoria critica del derecho. Enrique E. Mari et alii. Buenos Aires: Abeledo-Perrot, 1991, p. 236.

11. GADAMER, Hans-Georg. Ob. cit., p. 401.

12. MÜLLER, Friedrich. Juristische Methodik. 5. ed., Berlim: Duncker \& Humblot, 1993, pp. 145-146.

13. Por isso a articulação ser e dever-ser (a relação norma-fato) é mais do que uma questão da filosofia do direito; é uma questão da estrutura da norma jurídica tomada na sua transposiçăo prática e, por conseqüência, ao mesmo tempo uma questão da estrutura deste processo de transposição.

14. KELSEN, Hans. Teoria pura do direito, trad. de João Baptista Machado. 4. ed., Coimbra: Arménio Amado Editor, 1979, p. 467.

Revista da Faculdade de Direito da UFRGS, v. 18, 2000 
além dos textos, ao empreender a produção prática do direito.

Por isso tenho insistentemente afirmado inexistirem soluções previamente estruturadas, como produtos semi-industrializados em uma linha de montagem, para os problemas jurídicos. $\bigcirc$ trabalho jurídico de construção da norma aplicável a cada caso é trabalho artesanal. Cada solução jurídica, para cada caso, será sempre, renovadamente, uma nova solução. Por isso mesmo - e tal deve ser enfatizado - a interpretação do direito se realiza não como mero exercício de leitura de textos normativos, para o que, repito-o, bastaria ao intérprete ser alfabetizado.

6. Presta-se essa minha breve digressão a explicitar, e também fundamentar, a afirmação, que faço, de que, tal como ocorre em relação às decisões judiciais, a solu- ção atribuída pelos juristas, em seus pareceres, a cada quesito que lhes tenha sido proposto é resultado da interpretação dos textos e de determinada situação de fato (= de determinados fatos).

Distintos os fatos, outras serão as soluções (= normas jurídicas) a serem a eles aplicadas, ainda que desentranhadas dos mesmos, exatamente dos mesmos textos normativos dos quais foram desdobradas as primeiras soluções consideradas.

É a capacidade de discernir essa circunstância que faz o jurista e permite a contínua renovação da força normativa dos textos, diante da perplexidade dos apedeutas.

Aqui não é a caravana, mas o direito que passa - e não ao som de latidos, mas de algo assim como a canção de JOAQUÍN SABINA, "pior para o sol"!

\section{As Diversas Eficácias e seu Convívio no Conteúdo da Sentença. A Tese de Pontes de Miranda}

\author{
Fexnanda Pa \\ Advogado em Porto Alegre.
}

"Há expressões comuns a essas cinco situaçôes: a primeira situação é a mesma que era, daí dizer-se é ou não é; a segunda faz existir algo que não existia, ou deixar de existir o que existia; a terceira afirma que houve ou não houve, e impõe que não haja; a quarta resulta de ato de alguém que não a fez, porém mandou que se fizesse; a quinta faz passar o que existe a outro lugar onde não existia, porque at é que devia existir. (Pontes de Miranda)
0. Quando JULIUS HERMANN 17. VON KIRCHMANN, em 1847, pronunciou sua conhecida e cáustica conferência, "Jurisprudência não é Ciência", em sociedade jurídica berlinense jamais identificada, e na qual negou caráter científico à jurisprudência, não poderia ter-lhe passado pela cabeça, naquele momento, estivesse a sacudir, tão intensa e extensamente, com a ciência do direito, nem tampouco estivesse - e isso é para nós aqui e agora o mais expressivo - a bulir num de seus mais sensíveis pontos, qual seja, o do uso da linguagem e o sentido das palavras havido pelos doutrinadores do direito, sem o rigor técnico necessário, de modo a refletir, na conceituação de institutos jurídicos, maior precisão taxinômica, a lhes emprestar foros de cientificidade.

Essa imprecisão conceitual faz-se, por exemplo, particularmente sensível no tocante ao que se compreende, a rigor, por eficácia da sentença. $\mathrm{O}$ tema vem preocupando os mais doutos processualistas nacionais, sobretudo pela sutileza com que a palavra eficácia é usada e, conseqüentemen- 